\title{
Cyanidin induces apoptosis and differentiation in prostate cancer cells
}

\author{
VALERIA SORRENTI ${ }^{1}$, LUCA VANELLA $^{1}$, ROSARIA ACQUAVIVA $^{1}$, VENERA CARDILE $^{2}$, \\ SALVATORE GIOFRE ${ }^{3}$ and CLAUDIA DI GIACOMO ${ }^{1}$
}

\begin{abstract}
Departments of ${ }^{1}$ Drug Science, Biochemistry Section and ${ }^{2}$ Bio-Medical Sciences, Physiology Section, University of Catania, I-95125 Catania; ${ }^{3}$ Department of 'Scienze del Farmaco e Prodotti per la Salute', University of Messina, I-98168 Messina, Italy
\end{abstract}

Received March 24, 2015; Accepted May 11, 2015

DOI: 10.3892/ijo.2015.3130

\begin{abstract}
Several natural antioxidants, including anthocyanins, have been reported to have chemotherapeutic activity in vivo and in vitro. The aim of the present study was to delineate the anti-proliferative activity and the cytodifferentiation properties mediated by cyanidin-3-O- $\beta$-glucopyranoside (C3G) treatment in the DU145 and LnCap human prostatic cancer cell lines. C3G produced anti-proliferative effects through activation of caspase- 3 and induction of $\mathrm{p} 21$ protein expression. The reduced cell viability was associated with a clear increase of DNA fragmentation in both cell lines after C3G treatment. Since LnCap and DU145 exhibited differences in sensitivity to $\mathrm{C} 3 \mathrm{G}$ treatment, the redox state of these cells was further investigated by estimating the levels of ROS and GSH. C3G antioxidant activity was confirmed only in DU145 cell line. Treatment with $\mathrm{C} 3 \mathrm{G}$ increased the levels of tumor suppressor P75NGFR, indicating a possible role of $\mathrm{C} 3 \mathrm{G}$ in the acquisition of a normal-like cell phenotype. Results reported in the present study demonstrate that $\mathrm{C} 3 \mathrm{G}$, the most abundant anthocyanin in diet, may represent a new approach and highly effective strategy in reducing carcinogenesis. C3G may be considered a new therapeutic agent with both anti-proliferative and pro-differentiation properties.
\end{abstract}

\section{Introduction}

Cancer is a major public health problem in developed countries and mortality has been increasing, in spite of the enormous amount of research and rapid developments that have proceeded in the past decade. Prostate cancer (PC) is the most common cancer in men aged $>50$ years. PC represents one of the leading causes of cancer-related mortality in Western countries (1-3) and it is rapidly increasing in Asia (4).

Correspondence to: Dr Luca Vanella, Department of Drug Science, Biochemistry Section, University of Catania, Viale A. Doria 6, I-95125 Catania, Italy

E-mail: lvanella@unict.it

Key words: cyanidin, prostate cancer, apoptosis, cytodifferentiation
Prostate and early-stage PC depend on androgens for growth and survival. However, in advanced stages of PC, growth and development of epithelial cells become refractory to androgen effects and cells grow in an uncontrolled manner (5).

The main treatment of $\mathrm{PC}$ remains androgen ablation therapy; however, even though $>80 \%$ of $\mathrm{PC}$ responds to this therapy, almost all of these cases relapse in less than a decade and become refractory to treatment (3). Therefore, prevention of PC is especially important. The field of chemoprevention, using natural substances to prevent cancer, has become increasingly studied in recent years. A diet rich in fruits and vegetables has been reported to reduce the risk of common types of cancer and may prove useful in cancer prevention. Moreover, since less-differentiated tumors become resistant to a wide variety of cytotoxic drugs, considerable attention has been focused on chemoprevention with natural compounds as a new and alternative approach to cancer control. Epidemiological studies have shown the ability of dietary compounds to act epigenetically against cancer cells and to influence an individual's risk of developing cancer (6). Several natural antioxidants, in particular polyphenols, have been reported to exhibit chemotherapeutic activity both in vivo and in vitro (7-12).

Differentiation therapy is a recent experimental approach aimed to compel malignant cells to resume the process of maturation, differentiating into more mature or normal-like cells $(13,14)$. Tumor reversion by differentiation inducing compounds seems to be an extremely attractive anticancer therapy. Numerous drugs derive their antitumor activity from the ability to induce apoptosis or differentiation. The first differentiation agent found to be successful was all-transretinoic acid in the treatment of acute promyelocytic leukemia $(15,16)$. Our previous study demonstrates that ellagic acid, the most prevalent polyphenol in pomegranate, displays antiproliferative and pro-differentiation properties in two prostate cancer cell lines $(17,18)$.

Several studies have also focused on determining the pharmacological profile of a flavonoid of the anthocyanin class, cyanidin-3-O- $\beta$-glucopyranoside $(\mathrm{C} 3 \mathrm{G})$, which is widely spread throughout the plant kingdom and it is present in both fruits and vegetables of human diets $(19,20)$. One of the richest dietary source of $\mathrm{C} 3 \mathrm{G}$ is represented by pigmented orange (blood orange) typically growing in Sicily, Italy (21) as well as in Florida (22). In addition, C3G was found in its intact 
glycosylated form in both plasma and urine in humans and rats after oral intake of fruits $(23,24)$.

Besides showing a remarkable ability to reduce oxidative damage mediated by reactive oxygen species (ROS), even more effectively than other natural antioxidants $(25,26), \mathrm{C} 3 \mathrm{G}$ seems to be able to induce various modifications in different tumor cell lines and in particular in human colon carcinoma cells in vitro (27), as well as in rat colorectal cancer in vivo (28). It has also been reported that $\mathrm{C} 3 \mathrm{G}$ induces differentiation of HL-60 promyelocytic cells into macrophage-like cells and granulocytes (29) and revert human melanoma cells from a proliferating to a differentiated state (30).

In this study, we investigated the effect of $\mathrm{C} 3 \mathrm{G}$ on proliferation and differentiation of the androgen-sensitive (LnCap) and of the androgen-independent (DU145) prostate cancer cell lines. To investigate the capacity of $\mathrm{C} 3 \mathrm{G}$ to induce differentiation, receptor of nerve growth factor (p75NGFR) levels were evaluated. Anti-carcinogenic properties of $\mathrm{C} 3 \mathrm{G}$ were also evaluated by measuring the levels of proteins involved in apoptotic pathway such as caspase-3 and p21. In order to better understand the effects of C3G, DNA fragmentation was monitored by Comet assay. Moreover, since commonly used radio-therapeutic and chemotherapeutic drugs act influencing ROS levels, the ability of $\mathrm{C} 3 \mathrm{G}$ to modulate ROS production was also investigated. Finally, given the implication of glutathione in cell growth (31), the hypothesis of its implication in the mechanism of $\mathrm{C} 3 \mathrm{G}$ was also tested by measuring levels of non-proteic thiol groups ( $\mathrm{RSH})$ as an index of GSH content.

\section{Materials and methods}

Cell culture conditions. Human prostate cancer LnCap cells were purchased from American Type Culture Collection (Manassas, VA, USA) and grown in RPMI-1640 medium supplemented with $10 \%$ fetal bovine serum (FBS), $0.1 \%$ streptomycin-penicillin, $1 \%$ L-glutamine, $1 \%$ sodium pyruvate and $1 \%$ glucose. DU145 cells (human prostate carcinoma, epithelial-like cell line) were purchased from American Type Culture Collection and grown in DMEM supplemented with $10 \%$ fetal calf serum (FCS), $0.1 \%$ streptomycin-penicillin, $1 \%$ L-glutamine and $1 \%$ non-essential amino acids. Cells were incubated at $37^{\circ} \mathrm{C}$ in a $5 \% \mathrm{CO}_{2}$ humidified atmosphere and maintained at subconfluency by passaging with trypsin-EDTA (Gibco, NY, USA).

Cell viability. LnCap and DU145 cells were seeded at a concentration of $2 \times 10^{5}$ cells per well of a 96-well, flat-bottomed $200-\mu 1$ microplate. Cells were incubated at $37^{\circ} \mathrm{C}$ in a $5 \% \mathrm{CO}_{2}$ humidified atmosphere and cultured for $48 \mathrm{~h}$ in the presence and absence of different concentrations (3-200 $\mu \mathrm{M}$ ) of C3G (Polyphenols Laboratories, Sandnes, Norway). Four hours before the end of the treatment time, $20 \mu \mathrm{l}$ of $0.5 \%$ 3-(4,5-dimethylthiazol-2-yl)2,5-diphenyltetrazolium bromide (MTT) in phosphate-buffered saline (PBS) was added to each microwell. After incubation with the reagent, the supernatant was removed and replaced with $100 \mu$ l DMSO. The amount of formazan produced is proportional to the number of viable cells present. The optical density was measured using a microplate spectrophotometer reader (Thermo Labsystems Multiskan, Milano, Italy) at $\lambda=570 \mathrm{~nm}$. Results are expressed as percentage of viability.
Based on these experiments, C3G concentrations of 25, 50 or $100 \mu \mathrm{M}$ were used in the studies described below.

Lactic dehydrogenase release. Lactic dehydrogenase (LDH) activity was measured spectrophotometrically in the culture medium and in the cell lysates by analyzing the decrease in $\mathrm{NADH}$ absorbance at $\lambda=340 \mathrm{~nm}$ during the pyruvate-lactate transformation, as previously reported (32). Cells were lysed with $50 \mathrm{mM}$ Tris- $\mathrm{HCl}$ and $20 \mathrm{mM}$ EDTA pH 7.4 plus $0.5 \%$ sodium dodecyl sulfate, further disrupted by sonication and centrifuged at $13,000 \mathrm{~g}$ for $15 \mathrm{~min}$. The assay mixture ( $1 \mathrm{ml}$ final volume) for the enzymatic analysis contained $33 \mu 1$ of sample (5-10 $\mu \mathrm{g}$ of protein) in $48 \mathrm{mM}$ PBS pH 7.5 plus $1 \mathrm{mM}$ pyruvate and $0.2 \mathrm{mM} \mathrm{NADH}$. The percentage of LDH released was calculated as percentage of the total amount, considered as the sum of the enzymatic activity present in the cell lysate and in the culture medium. The optical density was measured using a Hitachi U-2000 dual beam spectrophotometer (Hitachi, Tokyo, Japan).

Immunocytochemistry. Experiments were carried out as described by Sigala et al (33). Specifically DU145, and LnCap cells, both untreated and C3G-treated, were plated on poly1-lysine-treated coverslips. Forty-eight hours later, cells were fixed for $5 \mathrm{~min}$ at $-20^{\circ} \mathrm{C}$ in methanol and washed in PBS. Endogenous peroxidases were inactivated at room temperature for 30 min with $1 \%$ hydrogen peroxide solution. Cells were permeabilized in PBS containing $10 \%$ normal donkey serum and $0.2 \%$ Triton X-100 and incubated with a 1:200 dilution of p75NGFR mouse monoclonal antibody (NeoMarkers, Freemont CA, USA). After extensive washes (3 times), the donkey anti-mouse biotinylated secondary antibody (Dako S.p.A., Milano, Italy) was added. Signal detection was carried out with the ABC kit (Dako). Omission of the primary antibody (not shown) and replacement of the primary antibody with goat normal serum were also used to define the non-specific signal.

Western blotting. DU145 and LnCap cells were cultured for $48 \mathrm{~h}$ in the presence or absence of different concentrations of $\mathrm{C} 3 \mathrm{G}$ and then suspended in $25 \mathrm{mM}$ Tris-buffered saline, $\mathrm{pH} 8.5$, containing $100 \mathrm{mM} \mathrm{NaCl}$ (Sigma-Aldrich, St. Louis, MO, USA), 7 mM mercaptoethanol (Merck KGaA, Darmstadt, Germany) and a protease inhibitor cocktail $(1: 1,000)$ (Sigma-Aldrich). The pellet was then sonicated for 3 cycles of $5 \mathrm{sec}$. The whole lysate was collected to evaluate caspase-3 and p21 expression by western blot analysis. Briefly, $50 \mu \mathrm{g}$ of lysate were loaded on a $10 \%$ SDS-PAGE and transferred to a nitrocellulose membrane (Bio-Rad Laboratoires, Hercules, CA, USA). The membranes were blocked with $3 \%$ fat-free milk in $10 \mathrm{mM}$ Tris- $\mathrm{HCl}(\mathrm{pH} 7.4), 150 \mathrm{mM} \mathrm{NaCl}$ and $0.05 \%$ TBST buffer, at $4^{\circ} \mathrm{C}$ for $2 \mathrm{~h}$ and then incubated with a 1:1,000 dilution of the primary antibody overnight at room temperature, with constant shaking. Primary polyclonal antibodies directed against caspase- 3 and p21 were purchased from Cell Signaling Technology, Inc. (Danvers, MA, USA). The membranes were then washed with TBS and probed with horseradish peroxidase-conjugated donkey secondary anti-mouse and anti-goat IgG at a dilution of 1:5,000. Chemiluminescence detection was performed with the ECL plus detection kit (Amersham, Biosciences Piscataway, NJ, USA) according to 


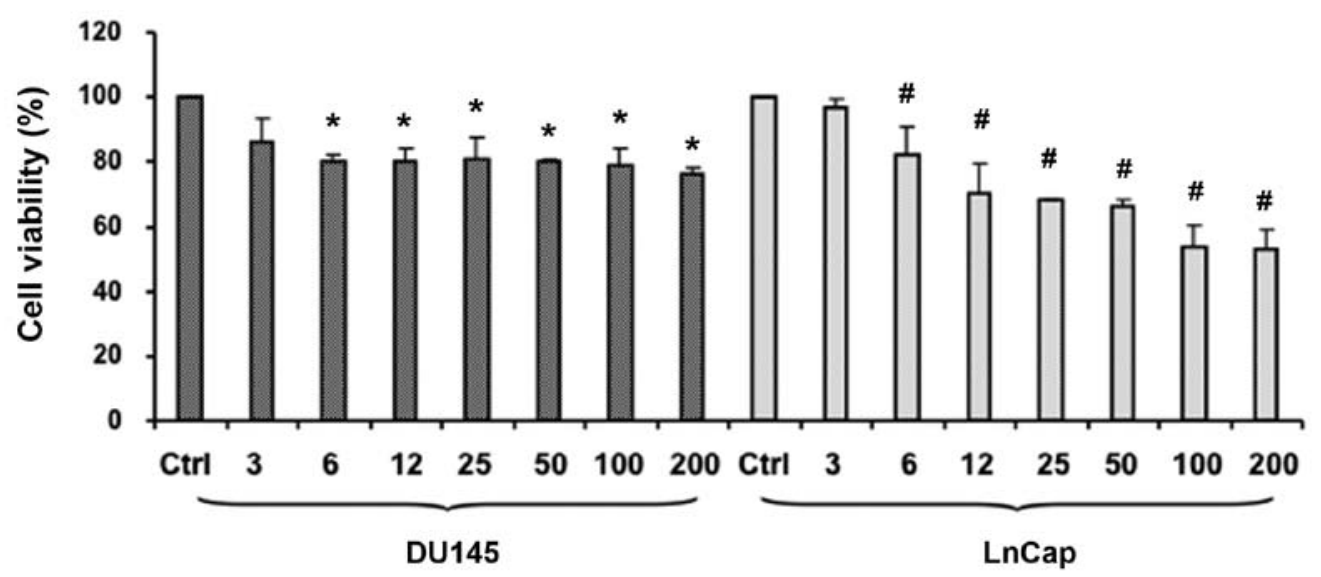

Figure 1. Cell growth inhibition, determined using MTT assay, of androgen-insensitive (DU145) and androgen-sensitive (LnCap) human prostate cancer cells untreated and treated with C3G at different concentrations (3-200 $\mu \mathrm{M})$ for $48 \mathrm{~h}$. Stock solution of the compound was prepared in DMSO. Data are the means \pm SEM from three experiments in triplicate. ${ }^{*} \mathrm{p}<0.05$ versus DU145 untreated cells. ${ }^{*} \mathrm{p}<0.005$ versus LnCap untreated cells.

the manufacturer's instructions. Western blots were quantified by densitometric analysis performed after normalization with $\alpha$-tubulin (Santa Cruz Biotechnology, Santa Cruz, CA, USA). Results were expressed as arbitrary units (AU).

ROS measurement. Determination of ROS was performed by using a fluorescent probe 2',7'-dichlorofluorescein diacetate (DCFH-DA) as previously described (17). The fluorescence [corresponding to the oxidized radical species 2',7'-dichlorofluorescein (DCF)] was monitored spectrofluorometrically (excitation, $\lambda=488 \mathrm{~nm}$; emission, $\lambda=525 \mathrm{~nm}$ ). The total protein content was evaluated for each sample, and the results are reported as percentage increase in fluorescence intensity/mg protein with respect to control (untreated) cells. Protein concentration was measured according to the method described by Bradford (34).

DNA analysis by Comet assay. The presence of DNA fragmentation was examined by single-cell gel electrophoresis (Comet assay) as previously reported (14). Briefly, 0.8-1 $\times 10^{5}$ cells were mixed with $75 \mu$ l low melting agarose, $0.5 \%$, and spotted on slides. The 'minigels' were maintained in lysis solution ( $1 \% \mathrm{~N}$-laurosil-sarcosine, $2.5 \mathrm{M} \mathrm{NaCl}, 100 \mathrm{mM}$ $\mathrm{Na}_{2}$ EDTA, $1 \%$ Triton $\mathrm{X}-100,10 \%$ dimethyl sulfoxide, $\mathrm{pH} 10.0$ ) for $1 \mathrm{~h}$ at $4^{\circ} \mathrm{C}$, denatured in a buffer $(300 \mathrm{mM} \mathrm{NaOH}, 1 \mathrm{mM}$ $\mathrm{Na}_{2}$ EDTA) for $20 \mathrm{~min}$ and finally electrophoresed in the same buffer at $13 \mathrm{~V}$ for $60 \mathrm{~min}$. At the end of the run, the minigels were neutralized in $0.4 \mathrm{M}$ Tris-HCl, $\mathrm{pH} 7.5$, stained with $100 \mu \mathrm{l}$ ethidium bromide $(2 \mu \mathrm{g} / \mathrm{ml})$ for $3 \mathrm{~min}$ and scored using a Leika fluorescence microscope (Leika, Wetzlar, Germany) interfaced with computer software (Cayman Sarin, Florence, Italy).

RSH evaluation. Since GSH is the principal and the most abundant non-proteic thiol in mammalian cells, the determination of RSH is indicative of cell GSH content. For RSH determination, DU145 and LnCap cells were cultured for $48 \mathrm{~h}$ in the presence or absence of different concentrations of $\mathrm{C} 3 \mathrm{G}$ and then washed in PBS. The pellets were then suspended in 0.25 M Tris buffer, containing $20 \mathrm{mM}$ EDTA, $\mathrm{pH}$ 8.2.

RSH levels were measured in $200 \mu \mathrm{l}$ of cell suspension as previously described (35). Briefly, this spectrophotometric assay is based on the reaction of thiol groups with 2,2-dithiobis-nitrobenzoic acid (DTNB) in absolute ethanol to give a colored compound absorbing at $\lambda=412 \mathrm{~nm}$. Since the DTNB method is strongly affected by $\mathrm{pH}$, the possibility of avoiding acids (trichloroacetic or sulfosalicylic acid) to precipitate proteins represents a remarkable advantage to ensure the accuracy of the assay. We then carried out the removal of proteins with an excess of absolute ethanol, followed by centrifugation at $3000 \mathrm{x} \mathrm{g}$ for $10 \mathrm{~min}$ at room temperature. Each value represents the mean \pm SEM of three experimental determinations for each sample. Results were expressed as nanomoles per milligram of protein.

Statistical analysis. Each experiment was repeated at a minimum of three times in triplicate. Statistical analysis was performed by using one-way analysis of variance followed by Dunnett's post hoc test for multiple comparisons with control. All statistical analyses were performed using the statistical software package SYSTAT, version 9 (Systat, Evanston IL, USA). A value of $\mathrm{p}<0.05$ was considered to be statistically significant.

\section{Results}

Effect of $C 3 G$ on cell viability and lactic dehydrogenase release. To investigate the effect of $\mathrm{C} 3 \mathrm{G}$ on proliferation of human prostate cancer cell line, a concentration-response graph (3-200 $\mu \mathrm{M})$ was established using a 48-h exposure time. Two human prostatic cell lines were evaluated for viability using the MTT assay. As seen in Fig. 1, LnCap cells were significantly more sensitive to $\mathrm{C} 3 \mathrm{G}$ treatment as compared to DU145. C3G treatment of LnCap decreased cell vitality in a concentration-dependent manner. Under the same experimental conditions $\mathrm{C} 3 \mathrm{G}$ displayed no cytotoxic effect against normal human epithelial cells (data not shown).

Based on these results, C3G concentrations of 25,50 or $100 \mu \mathrm{M}$ were used for further experiments. $\mathrm{LDH}$ release was measured to evaluate the presence of cell necrosis as a result of cell disruption. As seen in Table I, LDH release in treated cell did not differ from controls after $\mathrm{C} 3 \mathrm{G}$ exposure to different concentration $(25,50$ and $100 \mu \mathrm{M})$ for $48 \mathrm{~h}$. Thus suggesting that $\mathrm{C} 3 \mathrm{G}$ treatment induced apoptotic cell death. 


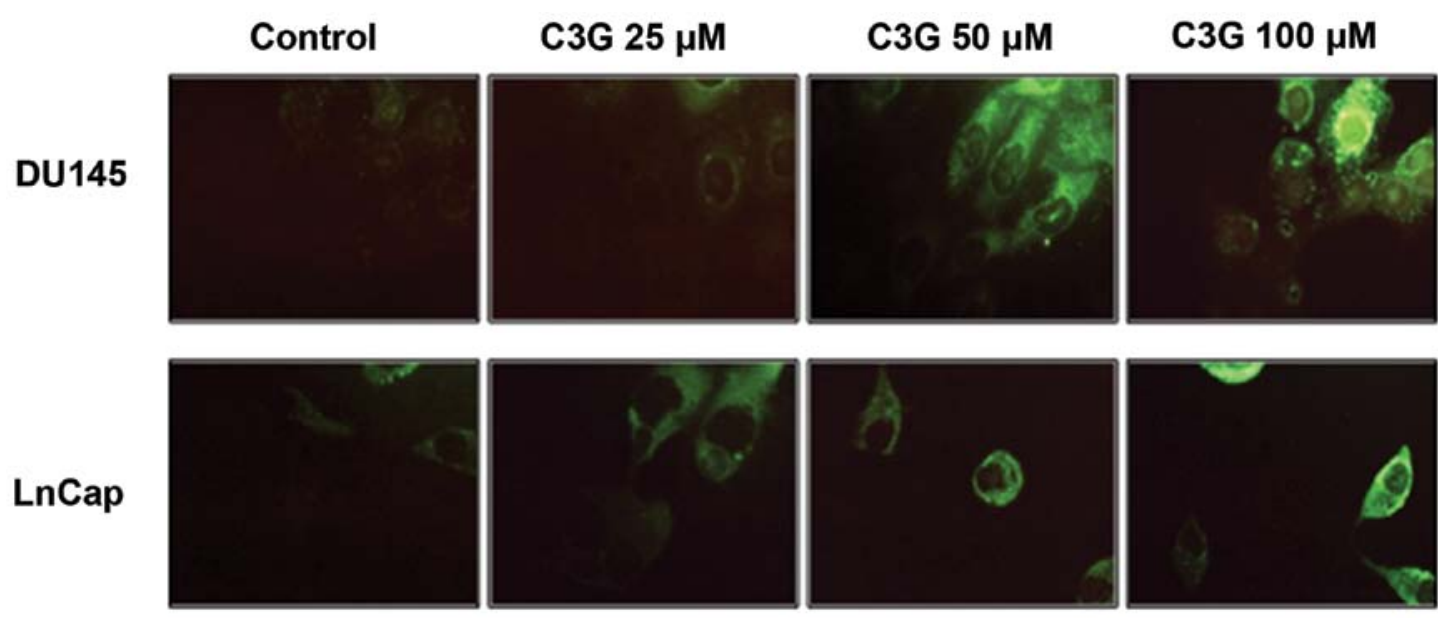

Figure 2. Light microscopy immunofluorescence analysis of p75NGFR distribution. Representative images of p75NGFR fluorescent intensity in DU145 and LnCap untreated and treated with C3G at three different concentrations $(25,50$ and $100 \mu \mathrm{M})$ for $48 \mathrm{~h}$.
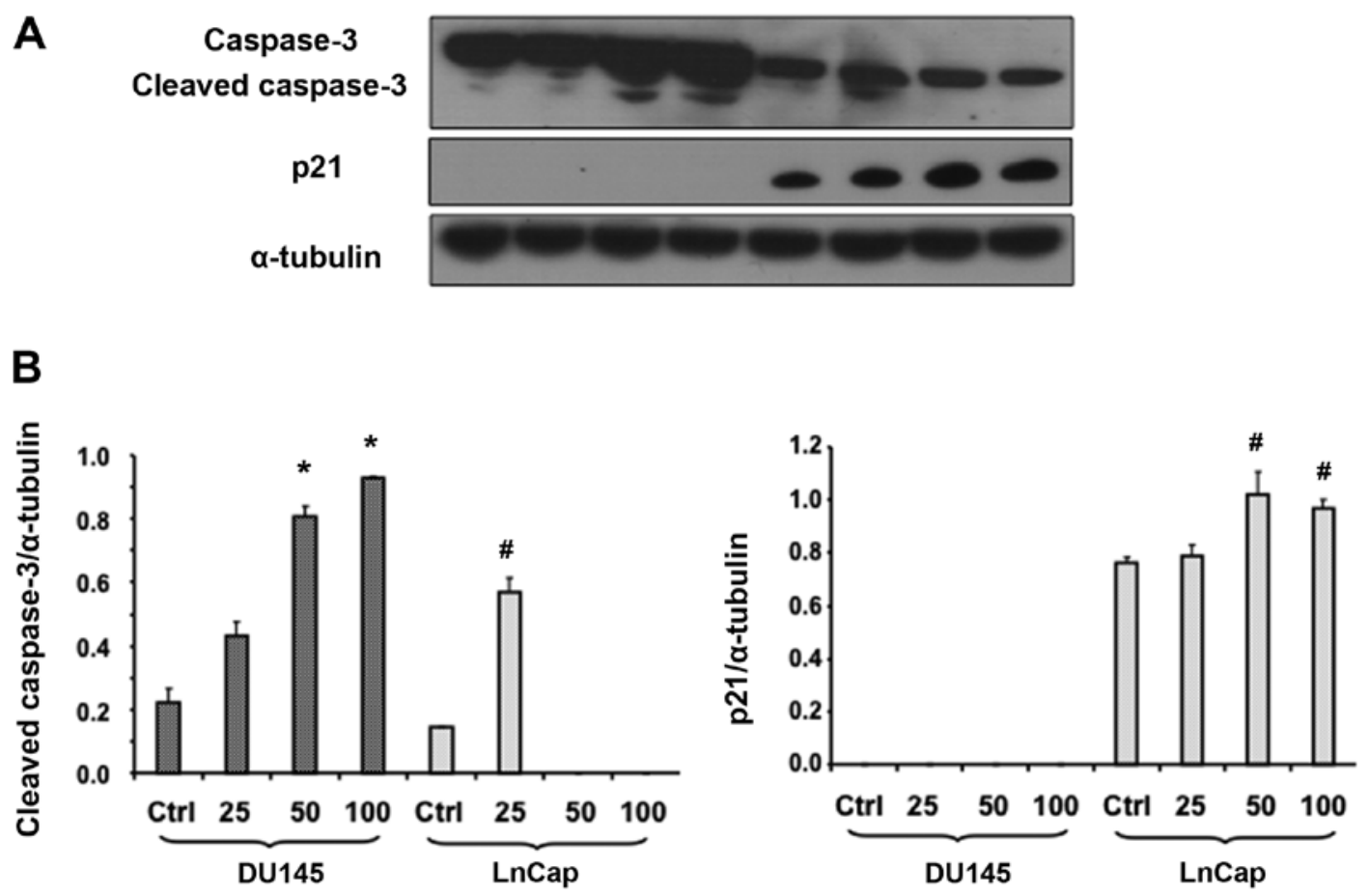

Figure 3. Representative western blotting (A) and densitometry analyses (B) of caspase-3 and p21 protein expression in cultured DU145 and LnCap cells untreated and treated with $\mathrm{C} 3 \mathrm{G}$ at different concentration $(25,50$ and $100 \mu \mathrm{M})$. Results represent the means \pm SEM of three experiments performed in triplicate. ${ }^{*} \mathrm{p}<0.05$, significant result of C3G vs DU145 control; ${ }^{*} \mathrm{p}<0.05$, significant result of C3G vs LnCap control.

Effect of C3G on p75NGFR levels. As previously described in our study, p75NGFR expression is downregulated in less differentiated prostate cancer cell line (14) and may represent a potential tumor suppressor gene in prostate cancer. To validate this hypothesis, the expression of p75NGFR in tumor epithelial cells was studied utilizing a fluorescence microscopy. The level of p75NGFR expression was significantly lower in the less differentiated cancer cell lines (DU145 and LnCap) compared to the hypertrophic cell line BPH-1 (14). Tumor epithelial cells cultured for $48 \mathrm{~h}$ in the presence of $\mathrm{C} 3 \mathrm{G}(25$, 50 and $100 \mu \mathrm{M})$, showed a significant increase in the green fluorescence intensity (Fig. 2).
Effect of C3G on caspase-3 and 21 expression. To investigate the possibility that activation of caspase- 3 and p21 could account for the decrease in cell proliferation and activation of the apoptotic pathway, we assessed the levels of these proteins after $48 \mathrm{~h}$ of culture in the presence of $\mathrm{C} 3 \mathrm{G}$ at different concentration $(25,50$ and $100 \mu \mathrm{M})$. Fig. 3 reports immunoblot and densitometric analysis of cleaved caspase-3 and p21 expression in untreated and C3G-treated cells. Our results showed that $\mathrm{C} 3 \mathrm{G}$ treatment resulted in activation of caspase-3, as demonstrated by a significant increase of its cleaved form, exclusively in the DU145 cells, whereas p21 expression was increased $(\mathrm{p}<0.05)$ only in the C3G-treated LnCap cells. It 
Table I. Cytotoxicity was determined by the LDH release assay in untreated and treated cultured cancer epithelial cells for 48 h with $\mathrm{C} 3 \mathrm{G}{ }^{\mathrm{a}}$

\begin{tabular}{lcc}
\hline & $\begin{array}{c}\text { DU145 } \\
(\% \text { LDH release })\end{array}$ & $\begin{array}{c}\text { LnCap } \\
(\% \text { LDH release })\end{array}$ \\
\hline Control & $13.24 \pm 0.13$ & $12.65 \pm 0.31$ \\
C3G 25 $\mu \mathrm{M}$ & $13.04 \pm 0.26$ & $11.32 \pm 0.53$ \\
C3G 50 $\mu \mathrm{M}$ & $10.83 \pm 0.44$ & $13.6 \pm 0.02$ \\
C3G 100 $\mu \mathrm{M}$ & $13.12 \pm 0.01$ & $12.53 \pm 0.11$ \\
\hline
\end{tabular}

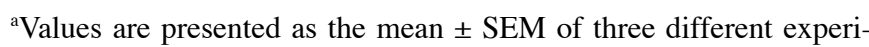
ments.

should be noted that the expression of p21 in the DU145 cell line was not detectable.

Effect of C3G on ROS and RSH levels. Since LnCap and DU145 exhibited differences in sensitivity to C3G treatment, we further investigated the redox state of these cells by estimating ROS and RSH levels under both the control and treated conditions. ROS levels were determined using the fluorescent probe, DCFH-DA. The intensity of fluores- cence was proportional to the levels of intracellular oxidant species. As shown in Fig. 4A, LnCap cells displayed a significant increase of basal ROS levels compared to DU145. Results confirmed the ROS-scavenging activity of $\mathrm{C} 3 \mathrm{G}$ in DU145 cells, thus causing a dose-dependent decrease of ROS production following $\mathrm{C} 3 \mathrm{G}$ treatment. Interestingly, exposure of LnCap cells to both 25 and $50 \mu \mathrm{M}$ C3G did not affect ROS production, whereas cell treatment with $100 \mu \mathrm{M}$ resulted in a significant increase in ROS levels compared to the untreated cells. In agreement with lower ROS levels, DU145 cells showed significantly higher basal GSH content than that found in LnCap cells (Fig. 4B). In addition to that, following C3G treatment, DU145 showed a significant $(\mathrm{p}<0.05)$ additional increase of GSH levels. $\mathrm{C} 3 \mathrm{G}$ had no effect on GSH levels in LnCap cells.

DNA fragmentation induced by treatment with $C 3 G$. In order to investigate the capability of $\mathrm{C} 3 \mathrm{G}$ to induce DNA damage, the typical Comet assay was performed on DU145 and LnCap after $\mathrm{C} 3 \mathrm{G}$ exposure to different concentrations $(25,50$ and $100 \mu \mathrm{M}$ ) for $48 \mathrm{~h}$. Results obtained showed that DNA fragmentation is clearly increased in DU145 and LnCap after treatment with $\mathrm{C} 3 \mathrm{G}$.

In fact, the DNA damage is extensive, as indicated by the large comet tail. As seen in Fig. 5, C3G exposure significantly increased DNA damage in a dose-dependent manner.
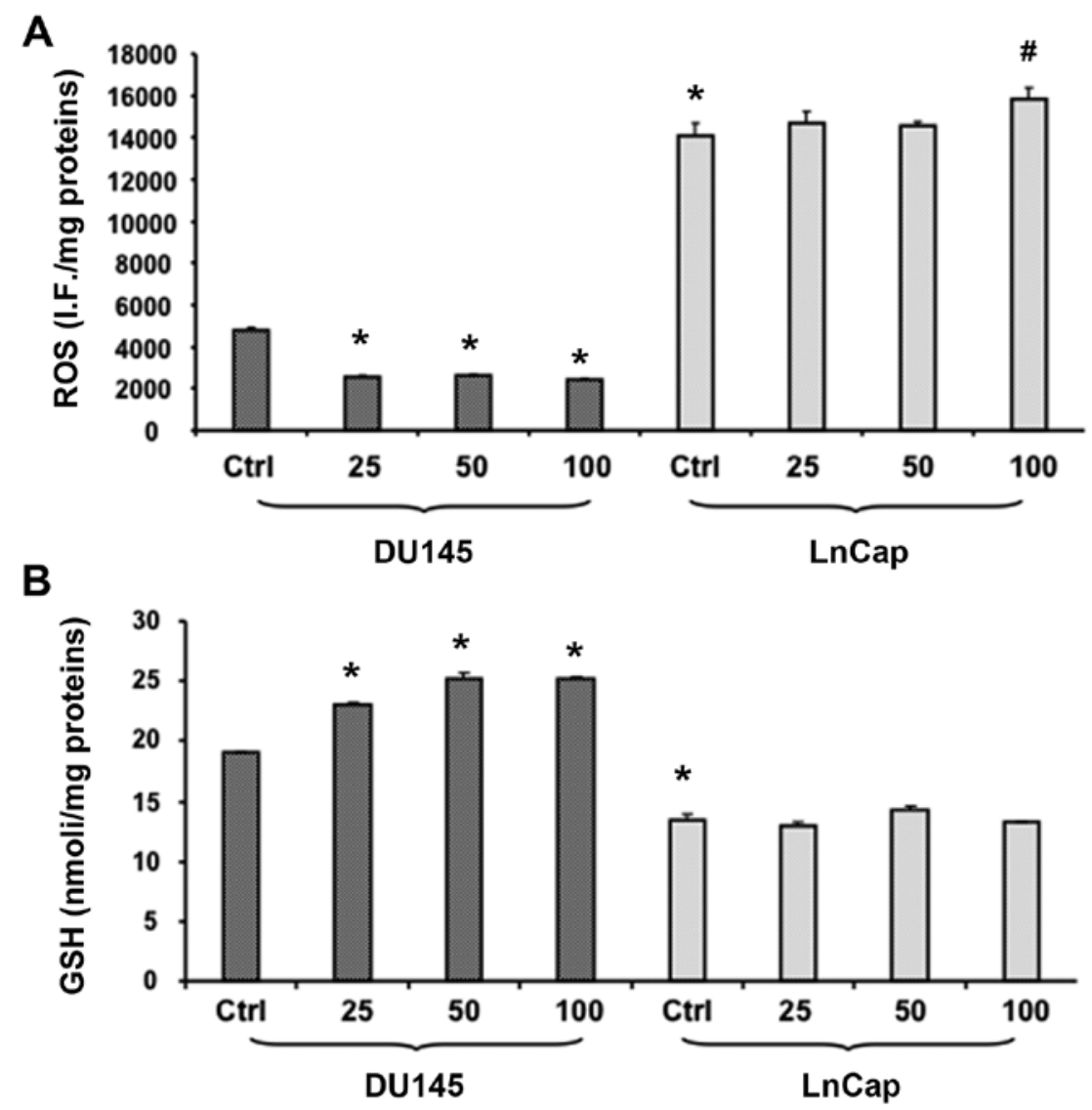

Figure 4. (A) Intracellular oxidants in DU145 and LnCaP cells untreated and treated for $48 \mathrm{~h}$ with C3G at different concentrations (25, 50 and $100 \mu \mathrm{M})$. Values represent the means \pm SEM of three experiments performed in triplicate. (B) Thiol groups in DU145 and LnCap cells untreated and treated for $48 \mathrm{~h}$ with $\mathrm{C} 3 \mathrm{G}$ at different concentrations $(25,50$ and $100 \mu \mathrm{M})$. Thiol groups are expressed as $\mathrm{nmol} / \mathrm{mg}$ protein. Values represent the means \pm SEM of three experiments performed in triplicate. ${ }^{*} \mathrm{p}<0.005$, significant result vs. untreated DU145 cells. ${ }^{\#} \mathrm{p}<0.05$, significant result vs LnCap control. 


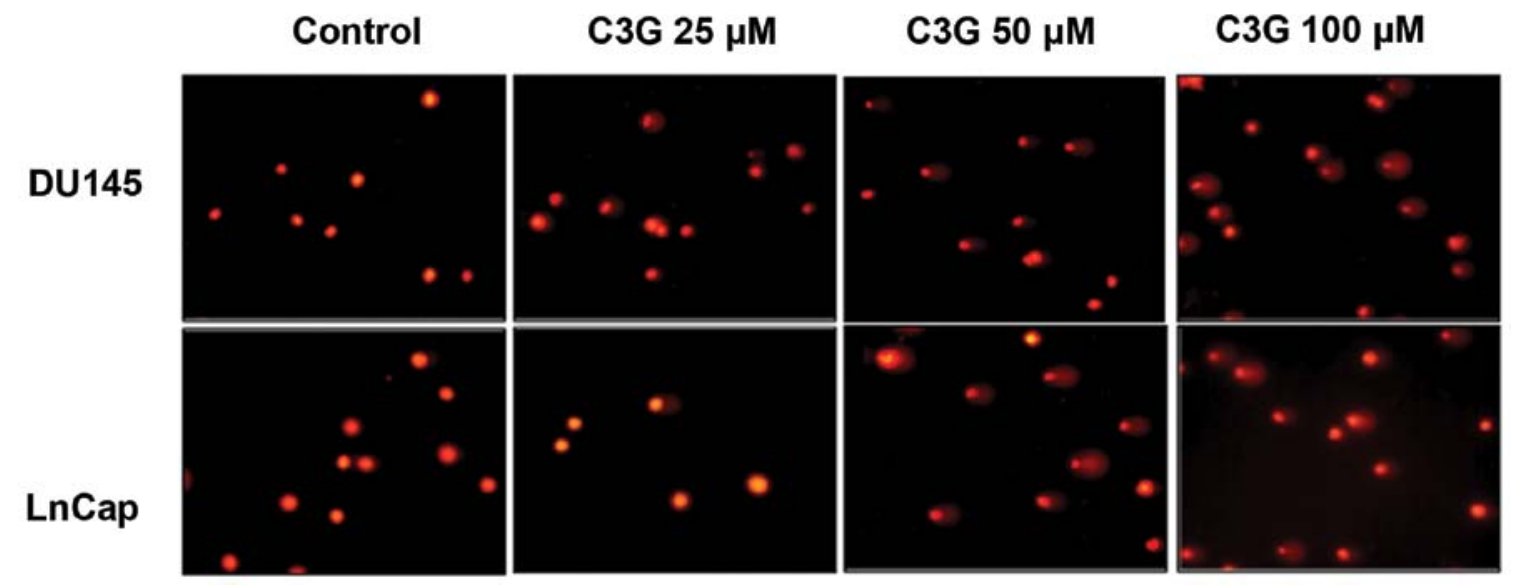

Figure 5. DNA strand break analysis performed on DU145 and LnCap cells treated with C3G for 48 h. Representative images of cancer cells untreated and treated with $\mathrm{C} 3 \mathrm{G}$ at three different concentrations $(25,50$ and $100 \mu \mathrm{M})$. A large comet tail is visible in DU145 and LnCap treated cells, indicating DNA strand breaks.

\section{Discussion}

Chemoprevention involves the administration of natural $(8,18)$ or synthetic agents $(36,37)$ designed to suppress the development or progression of cancer. Since less differentiated tumors become resistant to a wide variety of cytotoxic drugs, considerable attention has focused on chemoprevention with natural compounds as a new and alternative approach to cancer control (38). Epidemiological evidence indicates that polyphenolic compounds in diets are protective against cancer, and $\mathrm{C} 3 \mathrm{G}$ is abundant in many fruits such as pigmented orange, berry fruits and grapes. In order to study the anti-proliferative and pro-differentiating properties of $\mathrm{C} 3 \mathrm{G}$, we have chosen two prostate tumor cells, known to have differential chemotherapeutic response, namely, LnCap and DU145. LnCap and DU145 cells were chosen as prostate cancer experimental model, since these cell lines corresponds to different stages of prostate cancer. Indeed, the DU145, an androgen-independent prostate cancer cell line, is considered more invasive and less differentiated as compared to the androgen-dependent prostate cancer cell line LnCap. The loss of androgen receptor (AR), due to promoter methylation, represents an important hallmark of DU145 cell line (39). The growth and development of prostate cancer is initially androgen-dependent and androgen depletion therapy has been extensively explored as a strategy for prostate cancer prevention. Although androgen depletion is a valid strategy for the prevention and therapy of androgen-dependent PC, additional approaches are needed for advanced stages of PC that are androgen-independent. Our study shows that $\mathrm{C} 3 \mathrm{G}$ reduced the number of viable prostate cancer cells after $48 \mathrm{~h}$ of exposure when compared to the vehicle control cells. Although C3G induced apoptosis in both LnCap and DU145 cells, these latter were much less sensitive than LnCap cells. Evaluation of DNA damage by Comet assay, widely considered a versatile and highly effective tool in biomonitoring DNA integrity, shows that C3G, both in LnCap and DU145 cells, as shown in other cancer cell lines (40), induced DNA damage as evidenced by large comet tails. In addition, in the present report we demonstrate that $\mathrm{C} 3 \mathrm{G}$ treatment exerts pro-apoptotic effects by activating caspase- 3 and increasing p21 protein expression. As shown in Fig. 3, C3G induces both caspase-independent and caspase-dependent apoptotic cell death. C3G caused a significant increase of p21 expression, a negative regulator of the cell cycle, only in LnCap cells. In contrast, C3G caused activation of caspase-3 only in DU145 cells. These results suggest an apoptotic cell death, characterized by formation of apoptotic bodies, without an increase in cellular membrane breakage as demonstrated by no significant changes in LDH release observed in C3G-treated cells when compared to untreated cells. It should be noted that, while LnCap cells highly express p21, this protein is downregulated in DU145 cells. Cell cycle inhibitor p21 has been identified as one of the effector proteins upregulated by AR in order to achieve its tumor suppressor function. AR mRNA and protein levels detected in DU145 cell line are much lower than LnCap, an AR-positive cell line (39). Furthermore, DU145 cells are not able to engage AR to drive the expression of $\mathrm{p} 21$ and subsequently induce growth inhibition (41). DU145 cells lack necessary cofactors in order to achieve AR tumor suppressor. This may explain why DU145 are more resistant to C3G treatment.

The present study also demonstrates the possibility of modulating the growth of tumor cells through a new strategy. Cancer is a reversible state characterized by altered maturation in which the transformed phenotype can be suppressed by cytostatic agents and by the pharmacological induction of differentiation towards a benign form. Thus, compounds like polyphenols, capable of inducing differentiation $(14,42)$ may represent potential chemotherapeutic agents. We show for the first time that $\mathrm{C} 3 \mathrm{G}$, the most abundant anthocyanin in diet, inhibits cell growth/cell viability resulting in the reversion of both LnCap and DU145 cells from a proliferating to a differentiated state. Analysis of p75NGFR expression showed that it is decreased in PC and that the extent of p75NGFR loss is related to PC progression (43). Thus, p75NGFR has been proposed as a tumor suppressor molecule that mediates the anti-proliferative effects of NGF. Our data show that $\mathrm{C} 3 \mathrm{G}$ treatment increases p75NGFR expression, confirming the role of $\mathrm{C} 3 \mathrm{G}$ in the acquisition of a normal-like cell phenotype. 
ROS are known to be associated with many diseases by activating different signaling transductional/transcriptional pathways. Regardless of the mechanism, altered production of radical species may either sustain the life of tumor or cause its death. ROS are associated not only with initiation, but also with promotion and progression in the multistage carcinogenesis mode (44). Cancer cells often exhibit a high level of intrinsic oxidative stress due to an increased formation of ROS. In light of the important role of ROS in tumor progression, we measured the levels of ROS in both DU145 and LnCap cell lines. Our results indicate that the anti-proliferative/cytotoxic activity exhibited by $\mathrm{C} 3 \mathrm{G}$ was sustained by decreased endocellular ROS level in DU145 cells confirming the scavenging activity of $\mathrm{C} 3 \mathrm{G}$. On the other hand, surprisingly, C3G increased ROS levels in LnCap cells, but only at the highest concentration, suggesting that the same compound act differently in two different stages of prostate cancer. Cells employ many enzymatic and non-enzymatic antioxidants to counter the effect of ROS and to rebalance cell homeostasis. One of the most versatile protectors of such antioxidants is GSH. GSH performs several important physiological functions such as inactivation of oxygen-derived highly reactive species, detoxification of various types of xenobiotics and maintenance of the oxidative status of other antioxidants. The GSH content in cancer cells is particularly relevant in regulating mutagenic mechanisms, DNA synthesis, growth, and multidrug and radiation resistance. Cancer cell lines containing low GSH levels have been demonstrated to be much more sensitive than control cells to the effect of irradiation (45). Elevated GSH levels are observed in many malignant cells, and this makes the neoplastic tissues more resistant to chemotherapy (31). This is further confirmed by the fact that DU145 cells show significantly higher basal RSH content than that found in LnCap cells suggesting a reducing type of redox environment in DU145 cells compared to that of LnCap. The slight reduction in RSH observed in LnCap cells and its significant increase in DU145 cells further supports the results obtained by measuring ROS. An attractive hypothesis to explain the different RSH levels found in the present study might be just related to the higher replication rate of more malignant cells. Intracellular GSH levels fluctuate throughout the cell cycle depending on the phase of the cell cycle; elevated intracellular GSH levels have been observed upon cell cycle entry, followed by a significant reduction during $\mathrm{M}$ phase (46). Whether such differential cellular responses are cell type specific or related to alterations in mechanisms involved in GSH homeostasis are interesting questions that warrant further study. In conclusion, induction of apoptosis and differentiation are two promising cancer prevention strategies, as well as therapy. $\mathrm{C} 3 \mathrm{G}$ has drawn increasing attention because of its potential anticancer properties but little is known about the effects of $\mathrm{C} 3 \mathrm{G}$ on prostate cancer. We demonstrate that $\mathrm{C} 3 \mathrm{G}$, the most abundant anthocyanin in diet, displays anti-proliferative and pro-differentiation properties in two different prostate cancer cell lines. Our results provide a new perspective in the development of novel strategies for the prevention and treatment of PC through consumption of $\mathrm{C} 3 \mathrm{G}$ in an appropriate cancer prevention diet. It should be noted that, $\mathrm{C} 3 \mathrm{G}$ is active at concentrations corresponding to those achieved with food intake (range of $\mu \mathrm{M}$ ) and without any toxicity for non-tumorigenic cells.

\section{References}

1. Ferlay J, Parkin DM and Steliarova-Foucher E: Estimates of cancer incidence and mortality in Europe in 2008. Eur J Cancer 46: 765-781, 2010.

2. American Cancer Society: Prostate Cancer Statistics 2013. http:// www.cancer.org. Accessed May 20, 2013.

3. American Society of Clinical Oncology Prostate Cancer Statistics: http://www.cancer.net/prostate. Accessed May 20, 2013.

4. Ito K: Prostate cancer in Asian men. Nat Rev Urol 11: 197-212, 2014.

5. Arnold JT and Isaacs JT: Mechanisms involved in the progression of androgen-independent prostate cancers: It is not only the cancer cell's fault. Endocr Relat Cancer 9: 61-73, 2002.

6. Chen J and Xu X: Diet, epigenetic, and cancer prevention. Adv Genet 71: 237-255, 2010.

7. Kang NJ, Shin SH, Lee HJ and Lee KW: Polyphenols as small molecular inhibitors of signaling cascades in carcinogenesis. Pharmacol Ther 130: 310-324, 2011.

8. Weng CJ and Yen GC: Chemopreventive effects of dietary phytochemicals against cancer invasion and metastasis: Phenolic acids, monophenol, polyphenol, and their derivatives. Cancer Treat Rev 38: 76-87, 2012.

9. Russo A, Piovano M, Lombardo L, Vanella L, Cardile V and Garbarino J: Pannarin inhibits cell growth and induces cell death in human prostate carcinoma DU-145 cells. Anticancer Drugs 17: 1163-1169, 2006

10. Yim D, Singh RP, Agarwal C, Lee S, Chi H and Agarwal R: A novel anticancer agent, decursin, induces G1 arrest and apoptosis in human prostate carcinoma cells. Cancer Res 65: 1035-1044, 2005.

11. Cardile V, Scifo C, Russo A, Falsaperla M, Morgia G, Motta M, Renis M, Imbriani E and Silvestre G: Involvement of HSP70 in resveratrol-induced apoptosis of human prostate cancer. Anticancer Res 23C: 4921-4926, 2003.

12. Russo A, Berretta M, Cardile V, Lombardo L, Vanella L, Troncoso N, Garbarino J, Ignazio B and Li Volti G: Pharmacological induction of heme oxygenase-1 reduces KB cell viability: Role of carbon monoxide. J Carcinog \& Mutagen 2014, http:// dx.doi.org/10.4172/2157-2518.S8-009. Accessed April 16, 2014.

13. Waxman S: Differentiation therapy in acute myelogenous leukemia (non-APL). Leukemia14: 491-496, 2000.

14. Vanella L, Barbagallo I, Acquaviva R, Di Giacomo C, Cardile V, Abraham NG and Sorrenti V: Ellagic acid: Cytodifferentiating and antiproliferative effects in human prostatic cancer cell lines. Curr Pharm Des 19: 2728-2736, 2013.

15. Breitman T, Collins SJ and Keene B: Terminal differentiation of human promyelocytic leukemic cells in promyelocytic leukemic cells in primary culture response to retinoic acid. Blood 57: 1000-1004, 1981 .

16. Ohno R, Asou N and Ohnishi K: Treatment of acute promyelocytic leukemia: Strategy toward further increase of cure rate. Leukemia 17: 1454-1463, 2003.

17. Vanella L, Di Giacomo C, Acquaviva R, Barbagallo I, Cardile V, Kim DH, Abraham NG and Sorrenti V: Apoptotic markers in a prostate cancer cell line: Effect of ellagic acid. Oncol Rep 30: 2804-2810, 2013.

18. Vanella L, Di Giacomo C, Acquaviva R, Barbagallo I, Li Volti G, Cardile V, Abraham NG and Sorrenti V: Effects of ellagic Acid on angiogenic factors in prostate cancer cells. Cancers (Basel) 5: 726-738, 2013.

19. Wang H, Race EJ and Shrikhande AJ: Characterization of anthocyanins in grape juices by ion trap liquid chromatography-mass spectrometry. J Agric Food Chem 51: 1839-1844, 2003.

20. Seeram NP, Cichewicz RH, Chandra A and Nair MG: Cyclooxygenase inhibitory and antioxidant compounds from crabapple fruits. J Agric Food Chem 51: 1948-1951, 2003.

21. Amorini AM, Fazzina G, Lazzarino G, Tavazzi B, Di Pierro D, Santucci R, Sinibaldi F, Galvano F and Galvano G: Activity and mechanism of the antioxidant properties of cyanidin-3-O-betaglucopyranoside. Free Radic Res 35: 953-966, 2001.

22. Lee HS: Characterization of major anthocyanins and the color of red-fleshed Budd Blood orange (Citrus sinensis). J Agric Food Chem 50: 1243-1246, 2002.

23. Matsumoto $H$, Inaba $H$, Kishi $M$, Tominaga $S$, Hirayama $M$ and Tsuda T: Orally administered delphinidin 3-rutinoside and cyanidin 3-rutinoside are directly absorbed in rats and humans and appear in the blood as the intact forms. J Agric Food Chem 49: 1546-1551, 2001. 
24. Tsuda T, Horio F and Osawa T: Absorption and metabolism of cyanidin 3-O-beta-D-glucoside in rats. FEBS Lett 449: 179-182, 1999.

25. Ichikawa H, Ichiyanagi T, Xu B, Yoshii Y, Nakajima M and Konishi T: Antioxidant activity of anthocyanin extract from purple black rice. J Med Food 4: 211-218, 2001.

26. Kähkönen MP and Heinonen M: Antioxidant activity of anthocyanins and their aglycons. J Agric Food Chem 51: 628-633, 2003.

27. Briviba K, Abrahamse SL, Pool-Zobel BL and Rechkemmer G: Neurotensin-and EGF-induced metabolic activation of colon carcinoma cells is diminished by dietary flavonoid cyanidin but not by its glycosides. Nutr Cancer 41: 172-179, 2001.

28. Hagiwara A, Miyashita K, Nakanishi T, Sano M, Tamano S, Kadota T, Koda T, Nakamura M, Imaida K, Ito N, et al: Pronounced inhibition by a natural anthocyanin, purple corn color, of 2-amino-1-methyl-6-phenylimidazo[4,5-b]pyridine (PhIP)-associated colorectal carcinogenesis in male F344 rats pretreated with 1,2-dimethylhydrazine. Cancer Lett 171: 17-25, 2001.

29. Fimognari C, Berti F, Nüsse M, Cantelli-Forti G and Hrelia P Induction of apoptosis in two human leukemia cell lines as well as differentiation in human promyelocytic cells by cyanidin3-O-beta-glucopyranoside. Biochem Pharmacol 67: 2047-2056, 2004.

30. Serafino A, Sinibaldi-Vallebona P, Lazzarino G, Tavazzi B, Rasi G, Pierimarchi P, Andreola F, Moroni G, Galvano G, Galvano F, et al: Differentiation of human melanoma cells induced by cyanidin-3- $O$ - $\beta$-glucopyranoside. FASEB J 18 : 1940-1942, 2004.

31. Traverso N, Ricciarelli R, Nitti M, Marengo B, Furfaro AL, Pronzato MA, Marinari UM and Domenicotti C: Role of glutathione in cancer progression and chemoresistance. Oxid Med Cell Longev 2013: 972913, 2013.

32. Vanella L, Di Giacomo C, Acquaviva R, Santangelo R, Cardile V, Barbagallo I, Abraham NG and Sorrenti V: The DDAH/NOS pathway in human prostatic cancer cell lines: Antiangiogenic effect of L-NAME. Int J Oncol 39: 1303-1310, 2011.

33. Sigala S, Tognazzi N, Rizzetti MC, Faraoni I, Missale C, Bonmassar E and Spano P: Nerve growth factor induces the re-expression of functional androgen receptors and p75(NGFR) in the androgen-insensitive prostate cancer cell line DU145. Eur J Endocrinol 147: 407-415, 2002.

34. Bradford MM: A rapid and sensitive method for the quantitation of microgram quantities of protein utilizing the principle of protein-dye binding. Anal Biochem 72: 248-254, 1976.
35. Acquaviva R, Di Giacomo C, Sorrenti V, Galvano F, Santangelo R, Cardile V, Gangia S, D'Orazio N, Abraham NG and Vanella L: Antiproliferative effect of oleuropein in prostate cell lines. Int J Oncol 41: 31-38, 2012.

36. Romeo R, Giofrè SV, Garozzo A, Bisignano B, Corsaro A and Chiacchio MA: Synthesis and biological evaluation of furopyrimidine N,O-nucleosides. Bioorg Med Chem 21: 5688-5693, 2013.

37. Romeo R, Giofrè SV, Carnovale C, Campisi A, Parenti R, Bandini L and Chiacchio MA: Synthesis and biological evaluation of 3-hydroxymethyl-5-(1H-1,2,3-triazol) isoxazolidines. Bioorg Med Chem 21: 7929-7937, 2013.

38. Calabrese V, Cornelius C, Trovato A, Cavallaro M, Mancuso C, Di Rienzo L, Condorelli D, De Lorenzo A and Calabrese EJ: The hormetic role of dietary antioxidants in free radical-related diseases. Curr Pharm Des 16: 877-883, 2010.

39. Renis M, Calandra L, Scifo C, Tomasello B, Cardile V, Vanella L, Bei R, La Fauci L and Galvano F: Response of cell cycle/stressrelated protein expression and DNA damage upon treatment of $\mathrm{CaCo} 2$ cells with anthocyanins. Br J Nutr 100: 27-35, 2008.

40. Alimirah F, Chen J, Basrawala Z, Xin H and Choubey D: DU-145 and PC-3 human prostate cancer cell lines express androgen receptor: Implications for the androgen receptor functions and regulation. FEBS Lett 580: 2294-2300, 2006.

41. Litvinov IV, Antony L, Dalrymple SL, Becker R, Cheng L and Isaacs JT: PC3, but not DU145, human prostate cancer cells retain the coregulators required for tumor suppressor ability of androgen receptor. Prostate 66: 1329-1338, 2006.

42. Hagiwara Y, Kasukabe T, Kaneko Y, Niitsu N and Okabe-Kado J: Ellagic acid, a natural polyphenolic compound, induces apoptosis and potentiates retinoic acid-induced differentiation of human leukemia HL-60 cells. Int J Hematol 92: 136-143, 2010.

43. Yang Z, Chen H, Huo L, Yang Z, Bai Y, Fan X, Ni B, Fang L, $\mathrm{Hu} \mathrm{J}$, Peng J, et al: Epigenetic inactivation and tumor-suppressor behavior of NGFR in human colorectal cancer. Mol Cancer Res 13: 107-119, 2015.

44. Panayiotidis M: Reactive oxygen species (ROS) in multistage carcinogenesis. Cancer Lett 266: 3-5, 2008.

45. Meister A: Glutathione deficiency produced by inhibition of its synthesis, and its reversal; applications in research and therapy. Pharmacol Ther 51: 155-194, 1991.

46. Shaw JP and Chou IN: Elevation of intracellular glutathione content associated with mitogenic stimulation of quiescent fibroblasts. J Cell Physiol 129: 193-198, 1986. 